\title{
Humidification Performance of Humidifying Devices for Tracheostomized Patients With Spontaneous Breathing: A Bench Study
}

\author{
Yusuke Chikata, Jun Oto MD, Mutsuo Onodera MD, and Masaji Nishimura MD
}

\begin{abstract}
BACKGROUND: Heat and moisture exchangers (HMEs) are commonly used for humidifying respiratory gases administered to mechanically ventilated patients. While they are also applied to tracheostomized patients with spontaneous breathing, their performance in this role has not yet been clarified. We carried out a bench study to investigate the effects of spontaneous breathing parameters and oxygen flow on the humidification performance of 11 HMEs. METHODS: We evaluated the humidification provided by 11 HMEs for tracheostomized patients, and also by a system delivering high-flow CPAP, and an oxygen mask with nebulizer heater. Spontaneous breathing was simulated with a mechanical ventilator, lung model, and servo-controlled heated humidifier at tidal volumes of 300,500 , and $700 \mathrm{~mL}$, and breathing frequencies of 10 and $20 \mathrm{breaths} / \mathrm{min}$. Expired gas was warmed to $37^{\circ} \mathrm{C}$. The high-flow CPAP system was set to deliver 15, 30, and $45 \mathrm{~L} / \mathrm{min}$. With the $8 \mathrm{HMEs}$ that were equipped with ports to deliver oxygen, and with the high-flow CPAP system, measurements were taken when delivering 0 and $3 \mathrm{~L} / \mathrm{min}$ of dry oxygen. After stabilization we measured the absolute humidity $(\mathrm{AH})$ of inspired gas with a hygrometer. RESULTS: AH differed among HMEs applied to tracheostomized patients with spontaneous breathing. For all the HMEs, as tidal volume increased, AH decreased. At 20 breaths/min, AH was higher than at 10 breaths/min. For all the HMEs, when oxygen was delivered, AH decreased to below $30 \mathrm{mg} / \mathrm{L}$. With an oxygen mask and high-flow CPAP, at all settings, AH exceeded $30 \mathrm{mg} / \mathrm{L}$. CONCLUSIONS: None of the HMEs provided adequate humidification when supplemental oxygen was added. In the ICU, caution is required when applying HME to tracheostomized patients with spontaneous breathing, especially when supplemental oxygen is required. Key words: heat and moisture exchanger; HME; humidification; respiratory; mechanical ventilation; tracheostomy; spontaneous breathing; supplemental oxygen; CPAP. [Respir Care 2013;58(9):1442-1448. (C) 2013 Daedalus Enterprises]
\end{abstract}

\section{Introduction}

During everyday spontaneous breathing, inspiratory gases are normally heated and humidified in the nasal cavity and pharynx: by the time the second bronchial bifurcation is reached, inspired gas temperature is $37^{\circ} \mathrm{C}$ and absolute humidity (AH) is $44 \mathrm{mg} / \mathrm{L} .{ }^{1}$ In mechanically ventilated patients, because the anatomy that provides this

The authors are affiliated with the Department of Emergency and Critical Care Medicine, The University of Tokushima Graduate School, Tokushima, Japan. Mr Chikata is also affiliated with the Medical Equipment Center, Tokushima University Hospital, Tokushima, Japan.

Mr Chikata presented a version of this paper at the OPEN FORUM of the 58th AARC Congress, held November 10-13, 2012, in New Orleans, Louisiana. natural conditioning is bypassed by an artificial airway, administered gases require artificial conditioning. If humidification is inadequate, inspissation of airway secretions, destruction of airway epithelium, and hypothermia ${ }^{2}$ may occur. The American Association for Respiratory Care recommends that inspiratory gas temperature should be $>30^{\circ} \mathrm{C}$ and $\mathrm{AH}$ more than $30 \mathrm{mg} / \mathrm{L} \cdot{ }^{3}$ Heat and moisture

\footnotetext{
The authors have disclosed no conflicts of interest.

Correspondence: Masaji Nishimura MD, Emergency and Critical Care Medicine, The University of Tokushima Graduate School, 3-18-15 Kuramoto, Tokushima, Japan 770-8503. E-mail: nmasaji@clin.med. tokushima-u.ac.jp.
}

DOI: $10.4187 /$ respcare.02093 
exchangers (HMEs) and heated humidifiers are commonly employed to warm and humidify medical gases, and are widely used with adult patients undergoing mechanical ventilation. ${ }^{4}$ Their performance has been thoroughly investigated, and the results suggest that performance depends on brand, ${ }^{5}$ location in the ventilator circuit, tidal volume $\left(\mathrm{V}_{\mathrm{T}}\right)$, and minute volume. ${ }^{6,7}$

\section{See the Related Editorial on Page 1559}

HMEs are also applied to tracheostomized patients who are able to breathe spontaneously. The configuration of HMEs for tracheostomized patients with spontaneous breathing differs from applications for mechanically ventilated patients: some of the vapor in expired gas escapes to the atmosphere without being trapped by the HME, and room air that has bypassed the HME is inspired. Some HMEs have a port for delivering oxygen to hypoxemic patients, and administration of dry, cold oxygen may further decrease the temperature and $\mathrm{AH}$ of inspired gas. While the moisturizing ability of HMEs for daily use of active patients has been thoroughly evaluated, 8,9 we found no published results showing how well HMEs provide humidification to patients in ICUs. Consequently, for spontaneously breathing tracheostomized patients we studied the effects of spontaneous breathing parameters and oxygen flow on the performance of humidifiers.

\section{Methods}

We tested 11 models of HME, all commercially available in Japan, intended for use with spontaneously breathing tracheostomized patients. In addition we tested 2 other systems: an oxygen mask (Tracheomask, Intermed Japan, Tokyo, Japan) with a nebulizer heater (Aquatherm III, Hudson RCI, Durham, North Carolina), and a high-flow CPAP system (Airvo, Fisher \& Paykel, Auckland, New Zealand) for tracheostomized patients (Table 1). Using a mechanical ventilator (Puritan-Bennett 840, Covidien, Carlsbad, California), a lung model (TTL 1601, Michigan Instruments, Grand Rapids, Michigan), and a heated humidifier (MR730, Fisher \& Paykel, Auckland, New Zealand), we simulated real-life spontaneous breathing (Fig. 1). To simulate spontaneous breathing, the muscle and lung compartments of the lung model were connected, then the muscle compartment was inflated by the Puritan-Bennett 840 and the lung compartment inspired ambient air through an HME. Expired gas from the lung compartment went through a servo-controlled heated humidifier, and was warmed and humidified to $37^{\circ} \mathrm{C}$ and $100 \%$ relative humidity $(\mathrm{RH})$. One-way valves prevented mixing of inspired and expired gases. Our model was similar to that

\section{QUICK LOOK}

\section{Current knowledge}

Humidification of inspired gases following tracheostomy can be accomplished with heated humidification or a heat and moisture exchanger designed for tracheostomy. The performance of these heat and moisture exchangers is variable and can be altered by air leaks or the addition of oxygen.

\section{What this paper contributes to our knowledge}

In a model of spontaneous breathing, increasing the tidal volume and adding supplemental oxygen reduced the delivered humidity. At an oxygen flow of $3 \mathrm{~L} / \mathrm{min}$ the humidity fell below the minimum of $30 \mathrm{mg} \mathrm{H}_{2} \mathrm{O} / \mathrm{L}$ recommended by the American Association for Respiratory Care.

of Lellouche et al. ${ }^{5}$ The compliance of the lung compartment was set at $0.05 \mathrm{~L} / \mathrm{cm} \mathrm{H}_{2} \mathrm{O}$, and the ventilator was set in continuous mandatory ventilation mode with breathing frequencies of 10 and 20 breaths/min; $\mathrm{V}_{\mathrm{T}}$ of 300,500 , and $700 \mathrm{~mL}$; inspiratory time of $1.0 \mathrm{~s}$; and PEEP of $3 \mathrm{~cm} \mathrm{H}_{2} \mathrm{O}$. A ventilator self-test was performed before the study. Since the ventilator has compression volume correction, we did not measure the $\mathrm{V}_{\mathrm{T}}$ of the lung compartment. For testing, the oxygen mask with nebulizer heater was set at $\mathrm{F}_{\mathrm{IO}_{2}}$ of 0.33 and 0.98 , and the high-flow CPAP system was set at 15,30 , and $45 \mathrm{~L} / \mathrm{min}$. The highflow CPAP system had a port to deliver oxygen, as did 8 of the 11 HMEs: for each of these 9 systems, oxygen was delivered at 0 and $3 \mathrm{~L} / \mathrm{min}$ (temperature $24 \pm 0.2^{\circ} \mathrm{C}$ and RH 0\%).

We measured $\mathrm{AH}, \mathrm{RH}$, and temperature using a capacitance-type moisture sensor (Moiscope, Senko Medical, Tokyo, Japan, response time $3 \mathrm{~s}$ in the range $40-100 \%$ ) that was 2-point calibrated by a cooler/heater water source (HHC-51, Senkoika, Tokyo, Japan). After changing experimental settings, we waited for at least 1 hour. Because condensation on sensor surfaces compromises sensor performance, we did not insert sensors in the circuit during waiting. Usually we measured $\mathrm{RH}$ and temperature for $10 \mathrm{~min}$, and, after confirming stabilization of RH and temperature, we recorded $\mathrm{AH}, \mathrm{RH}$, and temperature for the last $5 \mathrm{~min}$. All experiments were performed in an air-conditioned room in which the ambient temperature was set at $24^{\circ} \mathrm{C}$. The ambient temperature and humidity were monitored with the same sensor. All signals from the hygrometer were led to an analog/digital converter and recorded at $50 \mathrm{~Hz} /$ channel with data-acquisition 
Table 1. Tested Humidifying Devices

\begin{tabular}{|c|c|c|c|c|c|c|}
\hline & $\begin{array}{l}\text { Absolute } \\
\text { Humidity* } \\
(\mathrm{mg} / \mathrm{L})\end{array}$ & $\begin{array}{l}\text { Water Loss* } \\
\left(\mathrm{mg} \mathrm{H}_{2} \mathrm{O} / \mathrm{L}\right)\end{array}$ & $\begin{array}{l}\text { Recommended } \\
\mathrm{V}_{\mathrm{T}} \text { Range } \\
(\mathrm{mL})\end{array}$ & $\begin{array}{l}\text { Dead } \\
\text { Space } \\
(\mathrm{mL})\end{array}$ & $\begin{array}{c}\text { Type of } \\
\text { Humidifier }\end{array}$ & $\begin{array}{c}\text { Oxygen } \\
\text { Port }\end{array}$ \\
\hline Trach-Vent+ & 27.0 & 8.4 & $>50$ & 10 & Passive & Yes \\
\hline Trach-Vent & 27.0 & 8.4 & $>50$ & 10 & Passive & No \\
\hline Tracheolife II & 28.5 & 11.0 & $100-1,000$ & 29 & Passive & Yes \\
\hline Aqua $+\mathrm{T}$ & 24.0 & 13.6 & $75-1,000$ & 15 & Passive & Yes \\
\hline Hydro-Trach II & 26.0 & ND & $<1,500$ & 19 & Passive & Yes \\
\hline Thermovent $\mathrm{T} 2$ & 25.0 & 15.6 & $>70$ & 11 & Passive & Yes \\
\hline Thermovent $\mathrm{T}$ & 25.0 & 15.6 & $>70$ & 9 & Passive & No \\
\hline Trachgard-HC & 24.0 & 20.0 & $75-1,000$ & 18 & Passive & Yes \\
\hline Aqua + TS & 24.0 & 13.6 & $75-1,000$ & 15 & Passive & Yes \\
\hline Trach Phone & 20.5 & ND & $50-1,000$ & 9.5 & Passive & Yes \\
\hline Pharma Trach Basic & 26.0 & 18.0 & $150-1,500$ & 12 & Passive & No \\
\hline Airvo & NA & NA & NA & NA & Active & Yes \\
\hline Tracheomask & NA & NA & NA & NA & Active & NA \\
\hline $\begin{array}{l}\text { * Manufacturer's data. } \\
\text { ND }=\text { no data available } \\
\text { NA }=\text { not applicable }\end{array}$ & & & & & & \\
\hline
\end{tabular}

software (Windaq, Dataq Instruments, Akron, Ohio). For each experimental setting we measured temperature and AH for 5 breaths. The results are expressed as mean \pm SD.

Analysis of variance and the Bonferroni test for multiple comparisons were used for overall comparisons be- tween with and without supplemental oxygen, and among 300,500 , and $700 \mathrm{~mL}$ of $\mathrm{V}_{\mathrm{T}}$. All statistical analysis was performed with statistical software (SPSS 11.01, SPSS, Chicago, Illinois) and $P$ values of $<.05$ were considered statistically significant. 


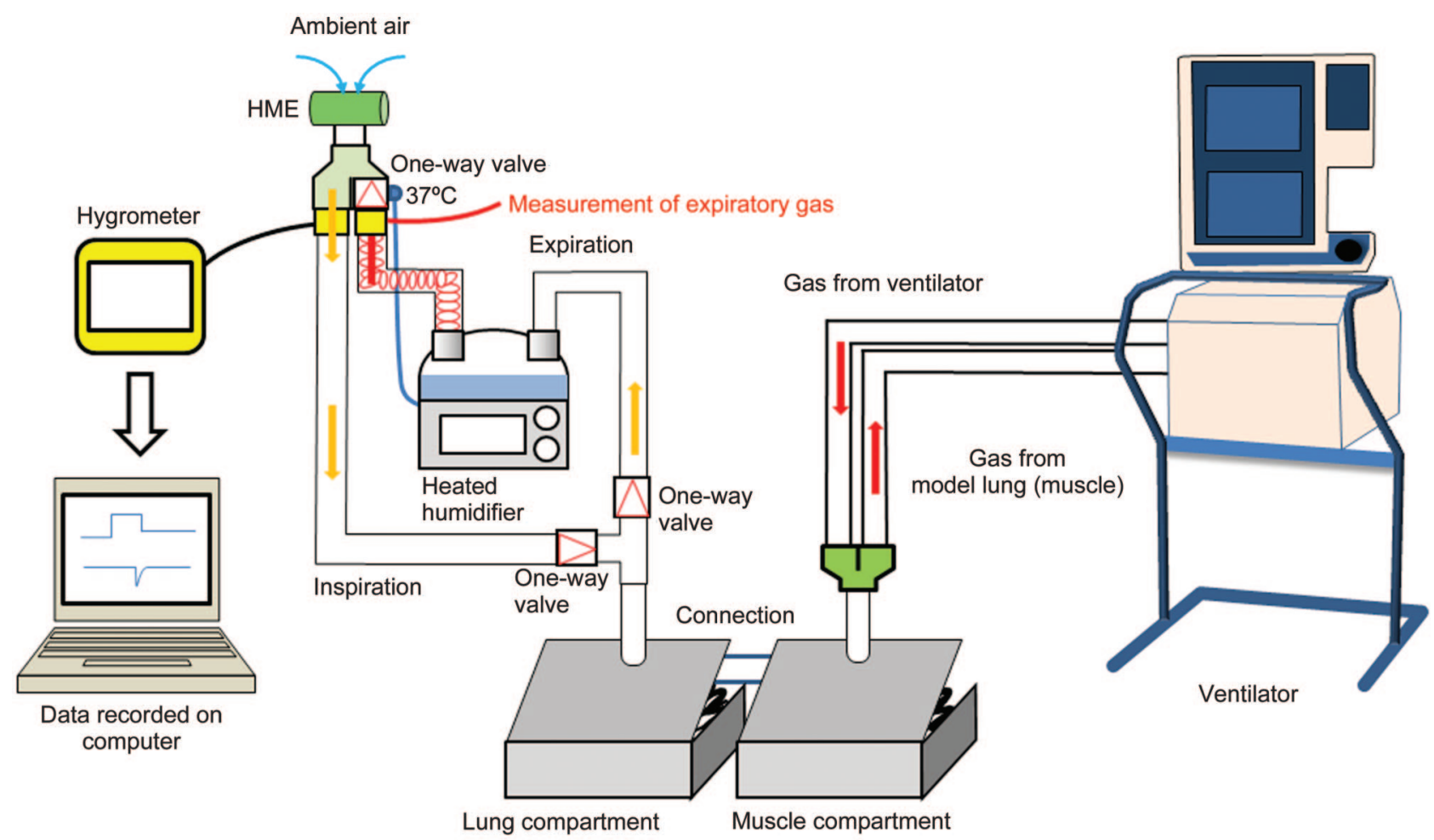

Fig. 1. Experimental setup. When the ventilator sends gas to the lung model's muscle compartment, the lung compartment attached to the muscle compartment starts inspiration. During simulated inspiration, ambient air is drawn into the lung compartment through the heat and moisture exchanger (HME) and hygrometer. When gas from the muscle compartment is sent to the ventilator, gas in the lung compartment is sent though the HME and expired into the ambient air. The expiratory circuit incorporated a heated humidifier, a limb with a heating wire, and a one-way valve, and the expiratory gas that passes through them is warmed to $36^{\circ} \mathrm{C}$ at the outlet of the heated humidifier, and to $37^{\circ} \mathrm{C}$ at the end of the limb. Expiratory absolute humidity was measured just before the one-way valve.

\section{Results}

Room temperature was $23.7 \pm 0.3^{\circ} \mathrm{C}$, and the ambient $\mathrm{RH}$ was $57.2 \pm 4.0 \%$. The $\mathrm{AH}$ of the simulated expired gas was $34.7 \pm 1.4 \mathrm{mg} / \mathrm{L}\left(\mathrm{RH} 100 \%\right.$ at $\left.32.5 \pm 0.8^{\circ} \mathrm{C}\right)$. Among the tested HMEs, AH ranged from 25.3 to $30.7 \mathrm{mg} / \mathrm{L}$. With high-flow CPAP, AH was $37.7 \pm$ $2.8 \mathrm{mg} / \mathrm{L}$, and with the oxygen mask with nebulizer heater $\mathrm{AH}$ was $31.9 \pm 2.2 \mathrm{mg} / \mathrm{L}$ (Table 2). When the $\mathrm{F}_{\mathrm{IO}_{2}}$ of the oxygen mask with nebulizer heater was changed from 0.33 to 0.99 , AH changed from $30.9 \pm$ $2.2 \mathrm{mg} / \mathrm{L}$ to $32.9 \pm 2.7 \mathrm{mg} / \mathrm{L}$. Adding oxygen at $3 \mathrm{~L} / \mathrm{min}$ decreased the $\mathrm{AH}$, and none of the HMEs continued to maintain AH above $30 \mathrm{mg} / \mathrm{L}$. In the high-flow CPAP system, with $3 \mathrm{~L} / \mathrm{min}$ oxygen (Fig. 2), AH was $37.8 \pm$ $2.5 \mathrm{mg} / \mathrm{L}$.

As $\mathrm{V}_{\mathrm{T}}$ increased, AH significantly $(P<.01)$ decreased in all the HMEs and in the system delivering high-flow CPAP via oxygen mask and nebulizer heater (Fig. 3). For all tested devices, as breathing frequency increased, $\mathrm{AH}$ increased: the percentage difference between breathing frequencies of 10 and 20 breaths/min was around 5\%.

\section{Discussion}

Taking into account the effects of supplemental dry oxygen, as well as of variations in $\mathrm{V}_{\mathrm{T}}$ and breathing frequency, we assessed the humidifying capabilities of 11 HMEs for tracheostomized patients with spontaneous breathing, of a system delivering high-flow CPAP, and of an oxygen mask with nebulizer. While $\mathrm{AH}$ was not evidently related to breathing frequency, it was profoundly affected by $\mathrm{V}_{\mathrm{T}}$ and oxygen supplementation. In each instance, when $3 \mathrm{~L} / \mathrm{min}$ of oxygen was supplied through HMEs equipped with oxygen ports, $\mathrm{AH}$ declined to below $30 \mathrm{mg} / \mathrm{L}$. Meanwhile, with all devices, as $\mathrm{V}_{\mathrm{T}}$ increased, AH decreased.

With 48 commercially available HMEs for mechanically ventilated patients, Lellouche et al found that only one in 3 devices maintained $\mathrm{AH}$ at $\geq 30 \mathrm{mg} / \mathrm{L} .{ }^{5} \mathrm{HMEs}$ for mechanically ventilated patients are configured differently than those for tracheostomized spontaneously breathing patients. All the HMEs we tested have a suction port through which the patient inspires ambient air. When $\mathrm{V}_{\mathrm{T}}$ increases, more ambient air is present in the inspired mixture. At $\mathrm{V}_{\mathrm{T}}$ of $300 \mathrm{~mL}, 8$ of the $11 \mathrm{HMEs}$ maintained $\mathrm{AH}$ at $\geq 30 \mathrm{mg} / \mathrm{L}$. 


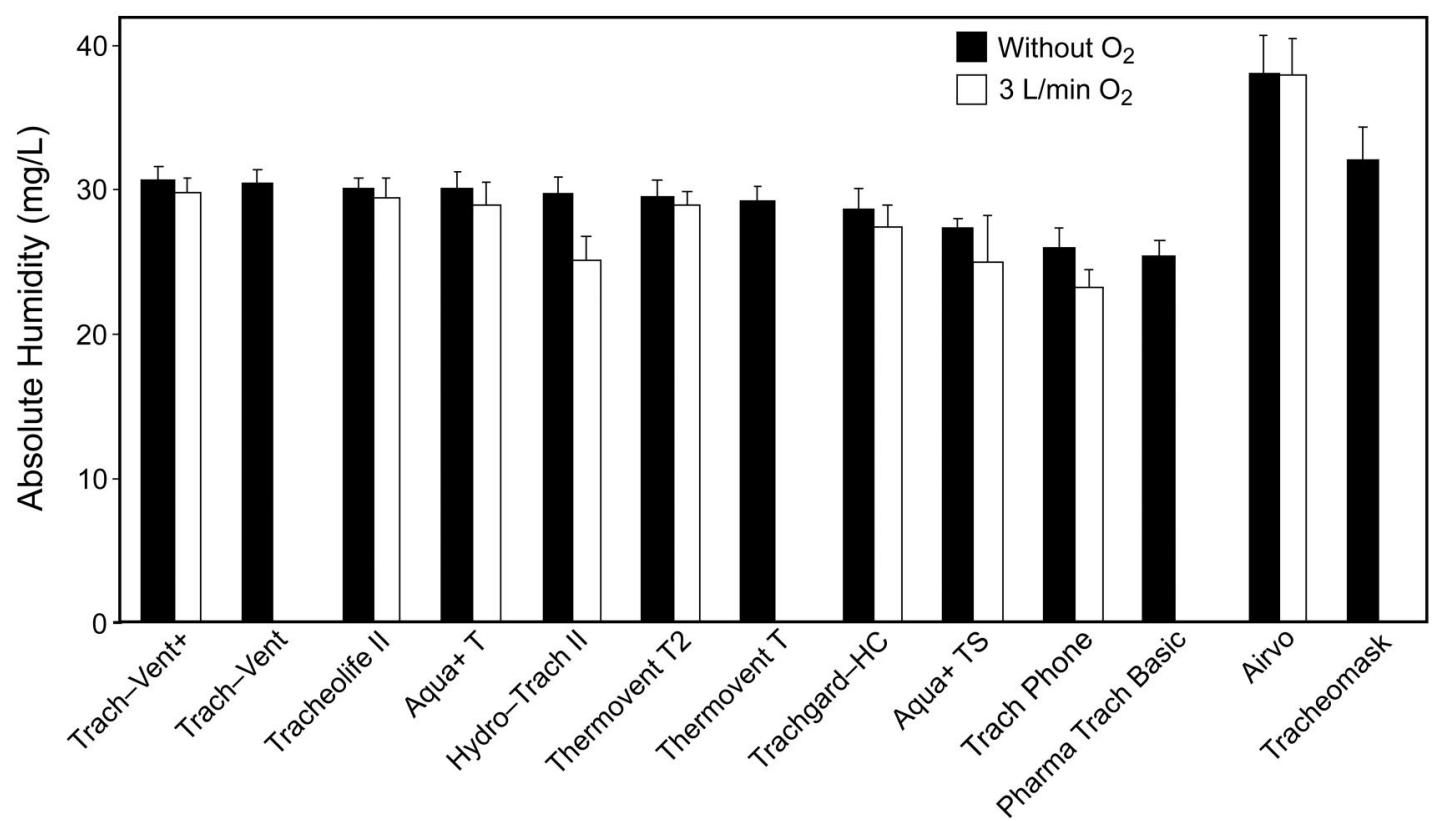

Fig. 2. Effect on absolute humidity of adding $3 \mathrm{~L} / \mathrm{min}$ dry oxygen. Absolute humidity fell below $30 \mathrm{mg} / \mathrm{L}$ with all the tested heat and moisture exchangers. The Airvo high-flow CPAP system was not affected by oxygen supplementation.

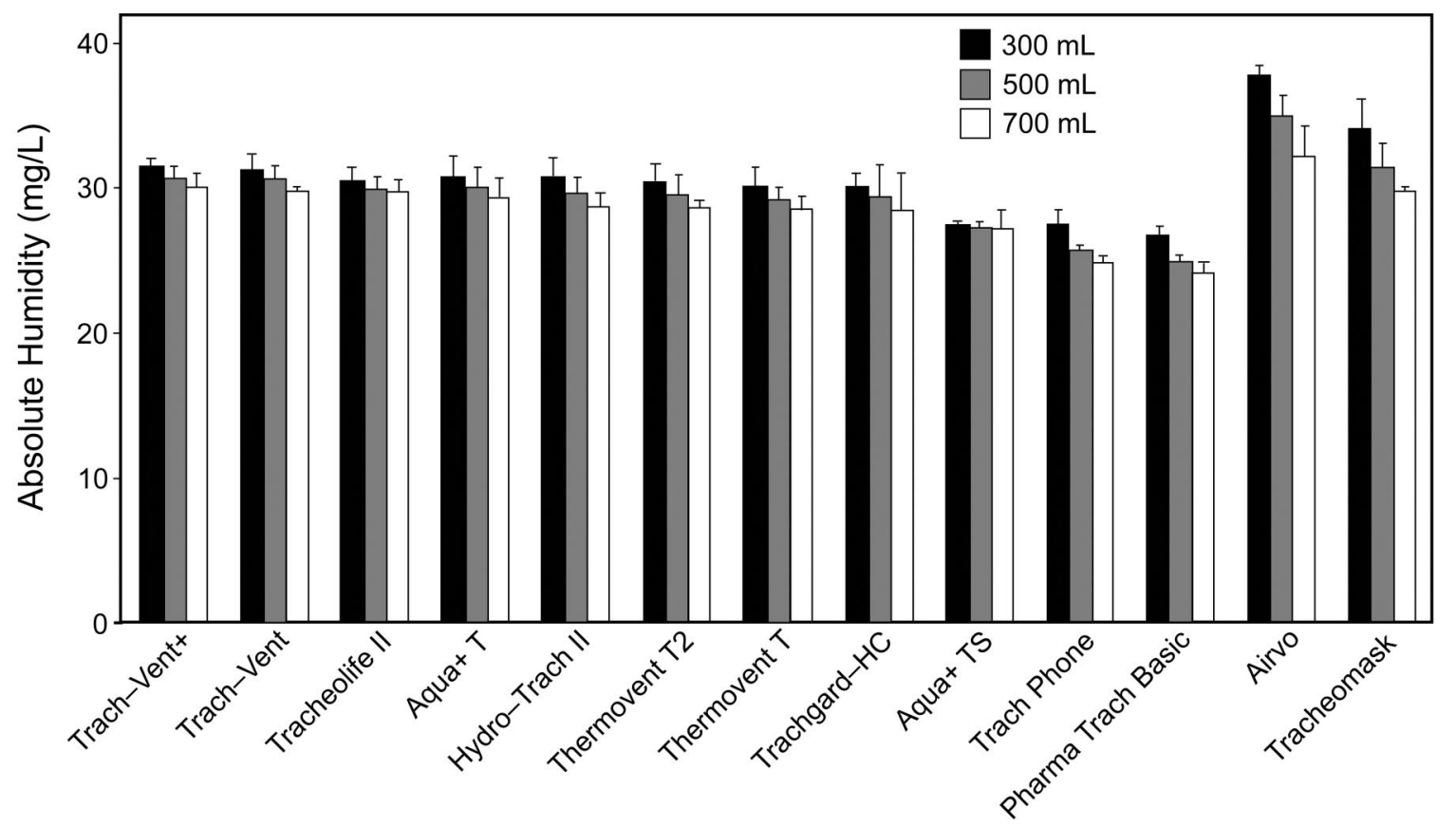

Fig. 3. Effect of tidal volume (without supplemental oxygen) on absolute humidity.

At $\mathrm{V}_{\mathrm{T}}$ of $700 \mathrm{~mL}$, only one of the HMEs maintained $30 \mathrm{mg} / \mathrm{L}$. $\mathrm{V}_{\mathrm{T}}$ greatly affected the performance of the tested HMEs for spontaneously breathing patients.

Assessing HMEs for mechanically ventilated patients, Lucato et al found that HMEs are more efficient with low- $\mathrm{V}_{\mathrm{T}}$ ventilation. ${ }^{7}$ HMEs for spontaneously breathing tracheostomized patients are applied differently than are those for mechanically ventilated patients. The use of a suction port causes the escape of some expiratory gas that does not pass through the HME, resulting in the loss of the vapor contained in that expired gas. HME performance is impaired by the volume loss to the atmosphere. ${ }^{10}$ These results are not directly comparable to the results we obtained for HMEs for mechanically ventilated patients. 
Table 2. Environment and Gas Conditions

\begin{tabular}{|c|c|c|c|c|c|}
\hline & \multirow{2}{*}{$\begin{array}{c}\text { Measured } \\
\text { Absolute } \\
\text { Humidity } \\
(\mathrm{mg} / \mathrm{L})\end{array}$} & \multicolumn{2}{|c|}{ Environment Conditions } & \multicolumn{2}{|c|}{ Expiratory Gas } \\
\hline & & $\begin{array}{c}\text { Temperature } \\
\left({ }^{\circ} \mathrm{C}\right)\end{array}$ & $\begin{array}{c}\text { Absolute } \\
\text { Humidity } \\
(\mathrm{mg} / \mathrm{L})\end{array}$ & $\begin{array}{c}\text { Temperature } \\
\left({ }^{\circ} \mathrm{C}\right)\end{array}$ & $\begin{array}{c}\text { Absolute } \\
\text { Humidity } \\
(\mathrm{mg} / \mathrm{L})\end{array}$ \\
\hline Trach-Vent+ & 30.7 & 23.7 & 10.8 & 32.2 & 34.1 \\
\hline Trach-Vent & 30.5 & 23.9 & 12.6 & 31.1 & 32.2 \\
\hline Tracheolife II & 30.1 & 22.8 & 12.0 & 33.1 & 35.8 \\
\hline Aqua $+\mathrm{T}$ & 30.0 & 23.6 & 10.2 & 32.1 & 33.9 \\
\hline Hydro-Trach II & 29.7 & 23.9 & 11.7 & 32.2 & 34.1 \\
\hline Thermovent $\mathrm{T} 2$ & 29.5 & 23.8 & 12.9 & 31.2 & 32.3 \\
\hline Thermovent $\mathrm{T}$ & 29.2 & 23.5 & 12.6 & 33.1 & 35.8 \\
\hline Trachgard-HC & 28.6 & 23.6 & 12.7 & 33.1 & 35.8 \\
\hline Aqua $+\mathrm{TS}$ & 27.3 & 23.9 & 13.0 & 33.0 & 35.6 \\
\hline Trach Phone & 26.0 & 23.5 & 12.7 & 32.1 & 33.9 \\
\hline Pharma Trach Basic & 25.3 & 23.7 & 11.9 & 33.2 & 36.0 \\
\hline Airvo & 37.7 & 23.8 & 12.8 & 33.3 & 36.2 \\
\hline Tracheomask & 31.9 & 23.9 & 13.0 & 33.1 & 35.7 \\
\hline
\end{tabular}

With no supplemental oxygen, AH differed among the investigated HMEs. These findings are in line with those in the Lellouche study. ${ }^{5}$ One of the great advantages of a bench study is that it enables investigation and comparison of medical devices under the same conditions. Even so, it was not possible to maintain all environmental and simulated spontaneous breathing conditions. Ambient temperature and humidity, and the temperature and $\mathrm{AH}$ of the gas expired from the lung model differed between the tested HMEs. Since these values are important determinants of HME performance, care is required when using these results to compare the performance of HMEs.

When $3 \mathrm{~L} / \mathrm{min}$ of oxygen was added, none of the HMEs with an oxygen port maintained $\mathrm{AH}$ at $\geq 30 \mathrm{mg} / \mathrm{L}$. As far as we know, this is the first study to evaluate the ability of HMEs to return vapor to spontaneously breathing tracheostomized patients. Supplemental oxygen also significantly $(P<.01)$ affected AH (see Fig. 3). ICU patients have diverse individual needs, but, after liberation from mechanical ventilation, supplemental oxygen is often required. Moreover, $\mathrm{V}_{\mathrm{T}}$ also differs between patients. To avoid complications from insufficient humidification, our findings suggest that it is prudent to consider use of a Tracheomask or a high-flow CPAP system, rather than an HME, in patients who require supplemental oxygen or who have spontaneous breathing with high $\mathrm{V}_{\mathrm{T}}$.

To accurately measure the $\mathrm{AH}$ of inspired gas, we inserted one-way valves to prevent overestimation owing to admixture, in the ventilator tubing, of water vapor from expired gases. As evaluated thoroughly in Zuur et al's study, when measuring the AH of breathing gas, it is important to control the durations of the inspiratory and expiratory phases. ${ }^{9}$ In our protocol the inspiratory time was $1 \mathrm{~s}$ and the expiratory time was either $5 \mathrm{~s}$ (at 10 breaths/ $\min$ ) or $3 \mathrm{~s}$ (at 20 breaths/min). If we had measured $\mathrm{AH}$ at the beginning of inspiration, we might have underestimated the actual values. We traced raw data and measured the highest value to evaluate HME performance. We cannot discount the possibility of underestimation, but, according to Zuur et al's study, any differences are likely to have been small. We suspect that the previously published higher $\mathrm{AH}(34 \pm 2.6 \mathrm{mg} / \mathrm{L})$ readings for the tested HMEs probably reflect contamination with fully humidified expiratory gas. On the other hand, using a servo-controlled heated humidifier to simulate physiological effects, our model maintained the expired gas temperature at $37^{\circ} \mathrm{C}$, resulting in slightly higher than previously reported $\mathrm{AH}$ of expired gas. ${ }^{5}$

Our study has several limitations. Obviously, with a lung-model simulation the findings do not directly correspond to clinical situations. Moreover, because our observation period was relatively short, our findings offer no evidence that HMEs can be used reliably and safely for prolonged periods in spontaneously breathing patients. Also, it was not possible to keep the ambient temperature and humidity precisely constant, which may have influenced our data.

\section{Conclusions}

In conclusion, with supplemental oxygen, humidification decreased below the American Association for Respiratory Care recommended value. When supplemental oxygen is required, humidification is insufficient with HME for spontaneously breathing tracheostomized patients with in the ICU.

\section{REFERENCES}

1. McFadden ER, Pichurko BM, Bowman HF, Ingenito E, Burns S, Dowling N, Solway J. Thermal mapping of the airways in humans. J Appl Physiol 1985;58(2):564-570. 


\section{Humidification Performance of Humidifying Devices for Tracheostomized Patients}

2. Bissonnette B, Sessler DI, LaFlamme P. Passive and active inspired gas humidification in infants and children. Anesthesiology 1989; 71(3):350-354.

3. Branson RD, Campbell RS, Chatburn RL, Covington J; American Association for Respiratory Care. AARC clinical practice guideline. Humidification during mechanical ventilation. Respir Care 1992; 37(8):887-890.

4. Branson RD. Humidification for patients with artificial airways. Respir Care 1999;44(6):630-641.

5. Lellouche F, Taillé S, Lefrançois F, Deye N, Maggiore SM, Jouvet P, et al; Groupe de Travail sur les Respirateurs de l'AP-HP. Humidification performance of 48 passive airway humidifiers: comparison with manufacturer data. Chest 2009;135(2):276-286.

6. Inui D, Oto J, Nishimura M. Effect of heat and moisture exchanger (HME) positioning on inspiratory gas humidification. BMC Pulm Med 2006;6:19.
7. Lucato JJ, Adams AB, Souza R, Torquato JA, Carvalho CR, Marini JJ. Evaluating humidity recovery efficiency of currently available heat and moisture exchangers: a respiratory system model study. Clinics (São Paulo) 2009;64(6):585-590.

8. Scheenstra RJ, Muller SH, Vincent A, Sinaasappel M, Zuur JK, Hilger FJM. Endotracheal temperature and humidity measurements in laryngectomized patients: intra- and inter-patient variability. Med Biol Eng Comput 2009;47(7):773-782.

9. Zuur JK, Muller SH, Vincent A, Sinaasappel M, de Jongh FH, Hilgers FJ. The influence of a heat and moisture exchanger on tracheal climate in a cold environment. Med Eng Phys 2009;31(7): 852-857.

10. Chikata Y, Sumida C, Oto J, Imanaka H, Nishimura M. Humidification performance of heat and moisture exchangers for pediatric use. Crit Care Res Pract 2012;2012:439267.

This article is approved for Continuing Respiratory Care Education credit. For information and to obtain your CRCE

(free to AARC members) visit

www.rcjournal.com

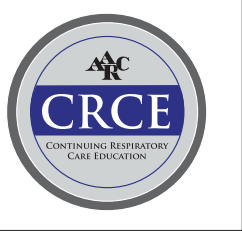

